\title{
O “ANTIPSICOLOGISMO" EM HUSSERL E HEIDEGGER: DA CONSCIÊNCIA AO DASEIN
}

\author{
Ísis Nery do Carmo ${ }^{1}$ \\ Universidade Federal da Bahia (UFBA) \\ https://orcid.org/0000-0001-5161-4772
}

\section{RESUMO:}

O nosso objetivo é propor um diálogo entre Husserl e Heidegger relacionando-os a partir da crítica que estes filósofos apresentam à investigação de viés naturalista acerca do homem, predominante na tradição filosófica. Para Husserl, o domínio do naturalismo representa a influência da Psicologia Experimental na filosofia, Heidegger, por sua vez, destaca a temática antropológica encontrada na história da filosofia. De acordo com o primeiro, o "psicologismo" acarreta na redução do homem aos seus componentes empíricos, para o segundo, o "antropologismo" equivale a um processo de coisificação do homem. O "psicologismo" e o "antropologismo" são reflexões inadequadas pois equiparam o homem ao objeto natural, isto é, são reflexões que não consideram o verdadeiro sentido de ser do homem, ignorando a consciência intencional e a existência. Logo, Husserl e Heidegger compartilham a tentativa de fazer a filosofia retornar sobre aquele âmbito que compõe propriamente o homem, ou seja, ambos filósofos defendem a desnaturalização da reflexão e desenvolvem a fenomenologia como o exercício de tal retorno.

PalaVRaS-CHAVE: Fenomenologia; Psicologismo; Antropologismo; Consciência; Existência.

\section{THE "ANTI PSYCHOLOGISM" IN HUSSERL AND HEIDEGGER: FROM CONSCIOUSNESS TO DASEIN}

\begin{abstract}
:
Our aim is to propose a dialogue between Husserl and Heidegger relating them from the criticism that these philosophers present to the investigation of naturalistic aspect about man, predominant in the philosophical tradition. For Husserl, the domain of naturalism represents the influence of Experimental Psychology on philosophy, Heidegger, in turn, highlights the anthropological thematic found in the history of philosophy. According to the first, "psychologism" entails the reduction of man to his empirical components, and to the second, "anthropologism" is equivalent to a process of man's reification. "Psychologism" and "anthropologism" are inadequate reflections because they equate man with the natural object, that is, reflections that do not consider man's true sense of being, ignoring intentional consciousness and existence. Thus Husserl and Heidegger share the attempt to make philosophy return to that true essence of man, that is, both philosophers advocate the denaturalization of reflection and develop phenomenology as the exercise of this return.
\end{abstract}

KEYWORDS: Phenomenology; Psychologism; Anthropologism; Consciousness; Existence.

1 Doutoranda em Filosofia na Universidade Federal da Bahia (UFBA), Bahia - Brasil. E-mail: isisnery@hotmail.com.

CARMO, Ísis Nery do. O "antipsicologismo" em Husserl e Heidegger: da consciência ao dasein. Griot : Revista de Filosofia, Amargosa/Bahia, v.17, n.1, p.326-336, junho/2018. 


\section{Introdução}

O presente trabalho desenvolve uma proposta de compreensão das obras dos filósofos Edmund Husserl e Martin Heidegger tomando como fio condutor do estudo aquilo que se denominou, na interpretação que tais autores propõem da história do pensamento ocidental, de psicologismo. Tal termo é frequentemente encontrado nos escritos husserlianos e, entretanto, é rarefeito nos textos do segundo pensador, onde encontraríamos, ao invés, a expressão antropologismo. Da obra husserliana, abordaremos as Investigações Lógicas e $A$ filosofia como ciência de rigor, da obra heideggeriana, nos limitaremos aos textos Introdução à Investigação Fenomenológica, Prolegômenos para uma Historia do conceito de tempo e Ser e Tempo.

Para Husserl, as ciências exatas da natureza, com o seu inquestionável sucesso, inspira todo o campo do saber, na filosofia tal busca por cientificidade está ancorada na Psicologia, disciplina que fundamentaria a Lógica e a Teoria do conhecimento ao investigar os fatos psicológicos que definem o homem enquanto sujeito do conhecimento. A Psicologia, sendo uma disciplina reconhecidamente científica, garantiria à Filosofia todo o rigor invejável das ciências naturais e esta, por conseguinte, disseminaria o modo de operar cientifico como um modelo de investigação. Assim, a expansão do modo de operar das ciências naturais para além dos seus limites, isto é, a tomada das ciências como paradigma para conhecer qualquer esfera de objetos, seria cunhado pelo termo "naturalismo", analogamente, a Psicologia, servindo à Lógica e Teoria do Conhecimento, produziria um "psicologismo". Em Husserl tais termos revelam uma crítica à aplicação indiscriminada da metodologia científica a objetos que não se adequam a tal modelo. Para o filósofo, a Psicologia Experimental é responsável por um erro grave: a naturalização da consciência.

Heidegger, por sua vez, levanta crítica às tentativas na Filosofia e na ciência de tratar o homem como um ente simplesmente dado, como coisa simplesmente existente, ocultando aquilo que o define realmente, isto é, a sua existencialidade. $O$ homem é marcado por um privilégio ôntico-ontológico que o retira das investigações empíricas ou psicológicas, exigindo um olhar fenomenológico para o questionar acerca do seu modo de ser. Compreendemos, então, que ambos filósofos fazem da sua filosofia uma denúncia à investigação de cunho naturalista acerca do homem, apontando para o equívoco que há na classificação do homem em categorias naturalistas, ao passo em que esta representa uma redução do ser-homem em sua essência. É neste sentido que destacamos a pertinência do objeto do presente artigo, acreditamos que as reflexões em torno do psicologismo funcionam como estímulo para o surgimento da fenomenologia, no seu primeiro impulso com Husserl assim como na sua radicalização com Heidegger.

\section{A Fenomenologia nascente contra o Psicologismo}

Nas suas famosas Investigações Lógicas, especificamente na Introdução ao segundo volume, Husserl esclarece a pertinência da sua obra, relacionando a Fenomenologia com as ciências e a Filosofia. Com o acelerado desenvolvimento das chamadas ciência naturais, os demais saberes esforçam-se para alcançar o mesmo 
patamar de sucesso e rigor. Na filosofia moderna, inaugurou-se uma reflexão acerca do conhecimento que definiu o homem enquanto sujeito que conhece o mundo a partir de sua subjetividade. Nesse contexto, a Psicologia em sua forma experimental adota um modelo análogo ao das ciências naturais, isto quer dizer que aqueles investigadores acreditavam que ao lado dos fenômenos físicos estavam os fenômenos psíquicos e ambos seriam conhecidos através de leis causais, visto que tanto os objetos das ciências quanto os objetos da Psicologia seriam objetos naturais, ou seja, pertenceriam à Natureza. A filosofia, enquanto Lógica e Teoria do Conhecimento, é afetada pela expansão do projeto cientificista quando a Psicologia lhe serve como fundamentação, avançando empiricamente no estudo dos estados mentais e estabelecendo as leis que regem o âmbito do conhecimento.

De acordo com o autor, a associação da Psicologia com a Filosofia falsifica e fragiliza os interesses da segunda, na medida em que anula as suas exigências de cientificidade. Uma reflexão que objetiva investigar as bases do conhecimento e as leis primeiras do pensar não pode ter como fundamento um saber que se sustenta em crenças acerca de um mundo fatual, existente de fato. Tais pressupostos empíricos presentes implicitamente nas ciências naturais permitem reflexões acerca dos fatos do mundo real' ${ }^{2}$ que são experimentados pelo homem, assim, haveria uma Natureza que se divide em fenômenos físicos e psíquicos; o real é posto em matéria e pensamento, em exterioridade e interioridade. Em termos gerais, a crença naturalista pode ser simplificada como uma redução do mundo ao que pensamos dele, isto é, o real é equivalente às nossas representações acerca dele, a realidade é acessível através dos nossos procedimentos mentais. $O$ que acontece é que, enquanto crença, esse pressuposto permaneceu inquestionado configurando a ingenuidade ${ }^{3}$ característica de todo naturalismo. Dessa forma, a investigação da Natureza carece de uma reflexão rigorosa: aquela deveria fundamentar-se em uma investigação primeira, que questionasse de modo puro a objetividade e validade do pensamento, isto é, uma teoria livre de pressupostos e, portanto, de fato científica. As pretensões da Psicologia - e de toda ciência - à cientificidade são desmontadas quando Husserl revela a fragilidade das crenças empiristas ocultas nas teses naturalistas.

Demonstrando a inconsistência do cientista científico-natural, Husserl reinventa a filosofia redefinindo, concomitantemente, sua relação com as ciências e, portanto, com a Psicologia. Retirando a filosofia da sua subordinação à esfera científica, o filósofo funda a fenomenologia como uma investigação neutra, isenta de

\footnotetext{
${ }^{2}$ De acordo com o filósofo, questões de existência são questões metafísicas posto que se baseam em pressupostos não averiguáveis fenomenologicamente: “A questão acerca da existência e da natureza do "mundo externo" é uma questão metafísica. A Teoria do Conhecimento, como esclarecimento geral sobre a essência ideal e sobre o sentido válido do pensamento cognoscente, abarca certamente a pergunta sobre se e em que medida é possível um saber ou um supor racional de objectos cousais "reais" que sejam principalmente transcendentes às vivências que os conhecem, e a que normas se deve conformar o sentido verdadeiro de um tal saber; mas ela não abarca a pergunta orientada empiricamente sobre se nós, homens, com base nos dados que nos são facticamente fornecidos, podemos efectivamente adquirir um tal saber, ou mesmo se temos a tarefa de realizar esse saber." (HUSSERl, 2007a, p. 47).

3 “Pelos seus pontos de partida, toda Ciência natural é ingênua. Para ela, a Natureza que pretende investigar, existe simplesmente. A existência de coisas - estáticas, móveis, variáveis, no espaço infinito, e temporais, no tempo infinito - compreende-se desde logo." (HUSSERL, 1965, p. 14)
}

CARMO, Ísis Nery do. O "antipsicologismo" em Husserl e Heidegger: da consciência ao dasein. Griot : Revista de Filosofia, 
pressupostos, que investiga a objetividade enquanto tal, e para isso, deve operar um retorno às vivências da consciência que estão na base dos conceitos da tradição filosófica que foram reproduzidos e adotados de modo, portanto, impróprio, isto é, sem a clareza quanto às suas origens. Termos como verdade, juízos, objetividade, conceito e evidência foram cristalizados durante o passar do tempo e, com isso, a intuição que os deu origem se perdeu, restando apenas, no vocabulário husserliano, uma "intuição vazia", isto é, uma mera opinião. Essa pureza conferiria à fenomenologia o poder de fundamentar os diversos saberes, pois, "[...] a Fenomenologia dá acesso às "fontes" de onde "brotam" ao conceitos fundamentais e as leis ideais da lógica pura, fontes às quais se deve, de novo, fazê-los retornar, se quisermos obter a clareza e distinção que é exigível [...]."(HUSSERL, 2007, p. 27).

$O$ resgate de tais fontes primordiais para toda construção teórica reorganiza e subverte a relação da filosofia com a Psicologia. Com a visão das essências, a fenomenologia retira a Psicologia do seu papel de fundamentação da Lógica, tomando o lugar outrora ocupado por aquela disciplina científica e transfere para a filosofia aquela função, concretizando assim, uma superação da abordagem naturalista, isto é, do psicologismo.

A Fenomenologia pura representa um domínio de investigações neutras,
no qual diferentes ciências tem as suas raízes. Por um lado, ela presta
serviço à Psicologia enquanto ciência empírica. No seu procedimento
intuitivo e puro, ela analisa e descreve, numa generalidade essencial -
especialmente enquanto fenomenologia do pensamento e do conhecimento
-, as vivências representativas, judicativas e cognitivas, que,
empiricamente apreendidas como classes de acontecimentos reais no
quadro da efectividade animal natural, a Psicologia submete a uma
investigação científica no elemento da experiência. (HUSSERL,
2007 a, p.27).

Anos mais tarde, em A Filosofia como ciência de rigor, Husserl faz do seu texto um manifesto contrário à influência das ciências naturais na filosofia, ao mesmo tempo em que exige rigor dos filósofos. Resgatando o espírito filosófico clássico, Husserl considera que a filosofia sempre aspirou ser uma ciência rigorosa, no sentido de tornar-se um saber supremo, a mais alta de todas as ciências, a representante do que há de mais nobre no homem. No entanto, apesar da sua pretensão à nobreza, a filosofia jamais alcançou o estágio que aspirou: a inconsistência latente na história do pensamento ocidental estaria refletida na relatividade da filosofia, no fato de que todas as proposições filosóficas serem discutíveis e estarem remetidas às escolas pertencentes. Como todos os juízos filosóficos dependem da convicção individual, a filosofia deveria se reestruturar, levando em conta as suas motivações supremas, porém, a transformação da filosofia em ciência filosófica não deveria significar uma subordinação às ciências da Natureza. Poderíamos pensar que a adoção do modelo científico seria suficiente para levar a filosofia ao seu estágio superior, Husserl nos faz desconfiar desta opinião corrente todas as vezes em que nos alerta para os perigos do psicologismo. Logo, a virada na filosofia requereria outro modo de operar, equivalente ao desenvolvimento da fenomenologia e a busca de fundamentação nesta por parte das disciplinas científicas. 
O famoso slogan fenomenológico, o "retornar às próprias coisas" se refere à mencionada volta às vivências que conferem objetividade e validade a toda e qualquer teoria. Quando tais vivências são negligenciadas, em nome de uma consciência que representa o mundo a um sujeito, podemos falar então de um contrassenso. Referindo-se ao naturalista, o autor nos diz que "o contra-senso que há nele, não é patente, mas oculta-se a ele próprio, residindo na sua naturalização da Razão." (HUSSERL, 1965, p. 11). Observando um cientista, é possível dizer que ele nega, teoricamente, tudo aquilo que possibilita a sua investigação. Em seu proceder, o naturalista "[...] é, porém, um idealista que estabelece e julga fundamentar teorias que negam precisamente as premissas do seu procedimento idealista [...]" (HUSSERL, 1965, p. 10), portanto, reduzindo a consciência aos seus caracteres reais, ele cai no mencionado contrassenso. Retornando ao âmbito primeiro daquilo que se apresenta à consciência, Husserl defendia uma abordagem dos caracteres ideais da consciência, que permaneceram invisíveis para a Psicologia ${ }^{4}$.

Assim como Husserl não recusa por absoluto a Psicologia ${ }^{5}$ - recusa o que poderíamos chamar de psicologização da filosofia e a sua consequência mais aguda, a naturalização da consciência - também não desconsidera o mundo fatual e a concretude da consciência real. A fenomenologia husserliana nos chama atenção para a crença numa conexão real entre a esfera subjetiva e a objetiva, como se o eu, de fato, se transportasse até o objeto do mundo, capturando-o. A objetividade não é alcançada por algum eu empírico, ela pertence à idealidade da consciência, especificamente, aos atos objetivantes que nos apresentam o mundo tal como ele é vivenciado. Nesse sentido, a consciência não pode ser reduzida a uma coisa que possui determinadas propriedades e conteúdos reais, a reflexão deve se dirigir aos caracteres puros dos atos que conferem objetividade ao pensamento, a partir de uma relação intencional entre a vivência e o objeto vivido.

Em si mesma, a consciência não é nada; retirando as suas vivências, não há o que possa ser dito acerca dela. Portanto, podemos afirmar que há uma relação de identidade entre a consciência e os seus atos, não restando nada além daquilo que ela vive. $\mathrm{O}$ ato não pode ser encontrado na consciência, da mesma forma, ele não é uma ação da consciência, tampouco haveria um objeto consciente como um conteúdo psíquico localizável nela. Logo, "[...] a própria consciência é a complexão das vivências. Mas o mundo não é jamais uma vivência do ser pensante. Vivência é visar-o-mundo, o próprio mundo é o objeto intencionado." (HUSSERL, 2007a, p. $422)$.

A consciência psicológica pode ser compreendida como uma esfera empírica orientada por leis que a antecedem, leis puras das vivências da consciência fenomenológica. Em relação à objetividade em geral, a existência de objetos reais é

\footnotetext{
${ }^{4}$ De acordo com Françoise Dastur, em Husserl: des mathématiques a l'histoire, a Psicologia, sendo uma ciência, não poderia alcançar o âmbito das vivências fenomenológicas. Pois, o retorno defendido por Husserl, para uma disciplina científica, seria equivalente à sua desconstrução, visto que, retornando às experiências originais, a ciência seria reconduzida à fonte de toda idealização, isto é, ao âmbito do pré-predicativo. Cf. DASTUR, 1995, p. 36-37.

5 "Notemos, no entanto, que o filósofo, pelo menos ao tempo das L.U., não afasta de modo absoluto a possibilidade de uma abordagem empírica a consciência; o que nos é afirmado é que tal abordagem é manifestamente insuficiente e falha à especificidade das vivências cognitivas." (PAISANA, 1992, p.39-40.)
}

CARMO, Ísis Nery do. O "antipsicologismo" em Husserl e Heidegger: da consciência ao dasein. Griot : Revista de Filosofia, 
indiferente, os objetos nos são apresentados intencionalmente, isto é, no modo de operar da consciência, tudo aquilo que sentimos, representamos, julgamos ou imaginamos, são conteúdo vividos, isto é, são vivências constituídas no ato do visar. O próprio objeto não é vivido, o que temos é o objeto como ele aparece no visar, em outras palavras, o que temos é o objeto no seu mostrar-se para nós. O mundo é, na fenomenologia nascente, isso que aparece dele e não aquilo que supostamente capturamos e arquivamos na consciência.

\section{A leitura heideggeriana do psicologismo}

Todo leitor das obras de Husserl e Heidegger sabe que as diferenças entre eles são indiscutíveis e isso a tal ponto que podemos ignorar a relação pessoal tão próxima que havia entre esses filósofos. As divergências entre eles se refletem na própria ideia de fenomenologia. A fenomenologia nasce, com o projeto husserliano, associada à lógica e à teoria do conhecimento, e se desenvolve e ganha força com seu pertencimento à hermenêutica e ao existencialismo, a partir de Heidegger. Nessa perspectiva, se tornou um desafio para a contemporaneidade o estudo dos possíveis pontos de encontro existentes entre tais filosofias. Apoiados na afirmação ${ }^{6}$ de Françoise Dastur, segundo a qual a proposta de Husserl e Heidegger de uma nova concepção de filosofia representa uma reação contra a sua assimilação pelo antropologismo - e suas formas, como o psicologismo -, tentaremos no presente artigo, desenvolver agora uma breve investigação acerca da crítica heideggeriana aos traços antropológicos da tradição filósofica, relacionando com a sua concepção de fenomenologia.

Anos antes da sua grande obra, Heidegger apresenta em 1923 um curso em Marburgo, intitulado Introdução à investigação fenomenológica, onde podemos observar um compartilhamento de ideias com a filosofia husserliana, especificamente com respeito às críticas à Psicologia.

O primeiro traço do efeito da naturalização da filosofia se encontra no fato
desta mesma tendência naturalista levar à naturalização da consciência.
[...] A unidade organizada desta má compreensão é o que se pode
denominar de psicologia experimental [...]. (HEIDEGGER, 2006, p. 78-
$79)^{7}$

Assim como o seu mestre, Heidegger acusa a filosofia de sofrer uma naturalização ao absorver o modo de operar científico, que culmina com a coisificação da consciência. Trata-se de uma má compreensão, pois a especificidade da consciência é desprezada em nome de um avanço científico, desse modo, podemos

\footnotetext{
6 "Even in his late writings, Husserl maintained that phenomenology was the restitution of the most ancient idea of philosophy, in other words, of a universal Science, the science of All. I intend to show that this task of rediscovering the full scope of the idea of philosophy against his modern reduction to anthropologism is also the leading motive of Heidegger's thought." (DASTUR, 2000, p.120.)

7 "El primer aspecto del efecto de la naturalización de la filosofia se encuentra en que esta misma tendencia naturalista lleva a la naturalización de la consciencia. [...] La organización unitaria de esta mala comprensión es lo que se puede denominar psicologia experimental [...]."
}

CARMO, Ísis Nery do. O "antipsicologismo" em Husserl e Heidegger: da consciência ao dasein. Griot : Revista de Filosofia, 
dizer que a fenomenologia tem como traço marcante a oposição à tendência naturalista e por isso defende uma nova esfera de reflexão.

Desfazer esta má compreensão, equivale, para Heidegger, em considerar de modo mais radical a consciência, isto é, radicalizar o questionar fenomenológico, levando adiante o projeto husserliano, ultrapassando, porém, o conceito fundamental da fenomenologia, qual seja, o conceito de consciência. Ora, se ambos autores estão unidos contra a descaracterização da filosofia e a influência da psicologia, por qual motivo Heidegger defende a superação da fenomenologia da consciência? Em outras palavras, o que motiva Heidegger a propor outra alternativa ao paradigma naturalista da filosofia? Aquilo que marca a consciência, o seu caráter intencional, embora seja resultado de um esforço por atingir propriamente o âmbito fenomenológico, ainda permanece, para Heidegger, na esfera da subjetividade.

Dirigindo-se aos seus objetos, a consciência já tem tais objetos como dados para ela, e por isso pode então indicá-los intencionalmente. O que possibilita o visar da consciência é uma abertura prévia para os entes que os tornam acessíveis a qualquer tipo de comportamento, seja consciente ou não. É preciso que as coisas surjam para nós para que então sejam apreendidas pela consciência em suas vivências. Tal abertura que precede os atos da consciência é articulada na compreensão de ser que pertence ao Dasein ${ }^{8}$. Assim como Husserl pensava ter retirado o homem do centro das suas investigações, da mesma forma Heidegger, com o termo Dasein, pretende ultrapassar as abordagens antropológicas fortemente presentes na história da filosofia. Sendo assim, Dasein indica o ser do homem, o seu privilégio ontológico de ser região de desencobrimento de sentidos de ser dos entes.

Sendo abertura, o Dasein não se deixa definir, não pode ser compreendido aos modos de uma coisa com determinadas propriedades, tampouco pode ser referido a uma estrutura subjetiva, o que quer dizer que "a "essência" deste ente está em ter de ser" (HEIDEGGER, 2009, p. 85) ou ainda, poderíamos dizer que "a "essência" da presença [Dasein] está em sua existência." (HEIDEGGER, 2009, p. 85). A partir da existência, o Dasein é alguma coisa, a existência é seu modo de ser exclusivo e não deve ser usado para descrever entes simplesmente dados. Logo, a analítica existencial - o estudo das estruturas da existência, chamadas de existenciais - se constitui em Ontologia Fundamental, e este é o retrato da fenomenologia em Ser e Tempo.

Se Husserl pretendia fazer da sua fenomenologia um estudo das leis puras da consciência, e este estudo alavancaria a filosofia em direção a uma ciência rigorosa, a mais alta ciência onde as demais disciplinas encontrariam fundamentação, Heidegger propõe o Dasein como instância primeira de abertura para sentidos de ser, defende que este é um dos objetos esquecidos da filosofia e a realização deste estudo configuraria a filosofia enquanto Ontologia Fundamental, ou seja, um saber que precede toda psicologia, biologia e antropologia.

Como vimos, para Husserl, a questão diretriz da filosofia é a objetividade ou a validade objetiva das nossas representações, por isso a filosofia deveria ser Teoria do Conhecimento e o fenômeno, portanto, seria aquilo que aparece nas vivências da consciência. Para Heidegger, a questão que move a filosofia é a questão do sentido de

\footnotetext{
${ }^{8}$ Diante da ausência de uma tradução satisfatória, optamos por deixar o termo Dasein como surge no idioma original do autor.
}

CARMO, Ísis Nery do. O "antipsicologismo" em Husserl e Heidegger: da consciência ao dasein. Griot : Revista de Filosofia, 
ser em geral, assim, a fenomenologia é Ontologia Fundamental, sendo o ser dos entes o fenômeno a ser explicitado. Desse modo, a ontologia só é possível enquanto fenomenologia e esta possui o seu sentido metodológico na hermenêutica, visto que deve-se interpretar aquele ente que possui compreensão de ser - o Dasein - a partir das estruturas da existência.

A recusa do termo "homem" e a opção pelo termo "Dasein" não são gratuitas, não se trata de uma mera substituição de palavras, pois,

\begin{abstract}
A explicação do Dasein não tem como motivo um especial interesse pela psicologia do homem, nem uma pretensão de responder à pergunta sobre o sentido e a finalidade de nossa existência, assunto do qual se ocupa as concepção de mundo.. (HEIDEGGER, 2007, p. 187)9
\end{abstract}

O que motiva a analítica do Dasein é, na verdade, uma necessidade de apresentar uma reflexão que fosse fiel ao seu objeto, considerando que a tradição filosófica - desde os gregos até os modernos - passou por cima daquilo que compõe ontologicamente o homem.

Definindo incessantemente o homem como uma coisa com determinadas características, um animal racional, um ser dotado de alma, razão, consciência ou transcendência, a filosofia ser perde na antropologia. Para Heidegger, a definição grega do homem como ser vivo dotado de alma e o paradigma teológico que fixa o homem como um ente criado à semelhança do seu criador, constituem obstáculos para uma adequada reflexão acerca do homem e assim levam a filosofia ao antropologismo. Nem mesmo o fundador da fenomenologia escapou daquela crítica, na interpretação heideggeriana.

A pessoa não é uma coisa, uma substância, um objeto. Com isso se ressalta e acentua a mesma coisa indicada por Husserl, ao exigir para a unidade da pessoa uma constituição essencialmente diferente das coisas da natureza. [...] Pertence à essência da pessoa apenas existir no exercício de atos intencionais e, portanto, a pessoa em sua essência não é objeto algum. [...] Ser psíquico não tem a ver, pois, com ser pessoa. Os atos são executados e a pessoa é executora de atos. Mas qual o sentido ontológico de "executar"? Como se deve determinar, de modo ontologicamente positivo, o modo de ser da pessoa? (HEIDEGGER, 2009, p. 92)

Toda reflexão lógica e epistemológica, de modo geral, carece de uma reflexão acerca daquele que pensa, isto é, acerca do existir. Na visão de Heidegger, a descrição das leis puras da consciência permanece atrelada a uma compreensão psicológica, ou seja, permanece vinculada àquele tipo de saber que Husserl pretendeu superar, pois, este se limita a pensar o homem enquanto preso às suas capacidades cognitivas, revelando uma ausência de questionamento acerca do modo de ser daquele que pensa. A aspiração por uma reflexão pura, que marca a fenomenologia, exigiria, de acordo com o autor de Ser e Tempo, a consumação do questionar husserliano, ultrapassando-o e abandonando o tema da consciência - que, neste sentido, ainda

\footnotetext{
9 “La explicación del Dasein no se da porque se tenga especial interés por la psicología del hombre, ni porque pretendamos dar respuesta a pregunta acerca del sentido y la finalidade de nuestra existencia, asunto que preocupa a las concepciones del mundo."
}

CARMO, Ísis Nery do. O "antipsicologismo" em Husserl e Heidegger: da consciência ao dasein. Griot : Revista de Filosofia, 
seria tema psicológico, com raízes na ciência empírica -, em direção à verdadeira singularidade do homem que está na existência, compreendida ontologicamente. Se a reflexão husserliana não foi tão longe, isto se deve aos entraves que os preconceitos psicológicos e antropológicos representam para o pensamento fenomenológico.

Devemos salientar ainda que Heidegger não está negando a consciência e os seus atos, o que a Ontologia Fundamental nos diz é que, se temos consciência de objetos, podemos construir proposições e erguer uma ciência, por exemplo, isto se deve ao fato de já estarmos lançados no mundo, pois é a partir dele as coisas nos aparecem. Para termos intencionalidade, faz-se necessário que os entes venham ao nosso encontro, logo, falta à filosofia da consciência uma reflexão acerca do sentido do pensamento, isto é, uma reflexão ontológica.

\section{Considerações finais}

Nosso trabalho não almeja a elaboração de uma comparação objetiva entre as filosofias de Husserl e Heidegger, tampouco pretendemos avaliar os resultados do debate com o psicologismo em cada um deles. Acreditamos que este não deve ser o modo de operar no estudo filosófico. Nossa proposta consiste em apresentar o que cada um deles desenvolveu acerca de um tema comum, a presença do psicologismo ou antropologismo na filosofia, compreendendo que tal temática poderia ser resgatada como um momento de diálogo entre os autores. Nesse sentido, teceremos agora comentários gerais acerca da relação entre os filósofos, as ciências, e o papel que a fenomenologia deveria assumir diante dos saberes científicos, a fim de concluirmos a nossa investigação.

Embora possamos observar com clareza a distância que há entre as Investigações Lógicas e Ser e Tempo, não podemos deixar de notar o quanto Heidegger se mostra grato aos ensinamentos husserlianos, como podemos observar na dedicatória da obra de 1926. Outros detalhes são também notáveis: como é sabido, Husserl recusou a analítica da presença, caracterizando-a como uma "antropologia filosófica", o que não poderia deixar de ser compreendida como traição aos olhos do autor da obra inaugural da fenomenologia. Heidegger, por sua vez, viu a obra husserliana como um capítulo da história da metafísica subjetivista ocidental.

A leitura feita por Husserl da obra Ser e Tempo é compartilhada por outros tantos filósofos e estudiosos. Na base desta opinião encontramos o conceito heideggeriano de mundo, relacionado à existência - visto que é um existencial - o que quer dizer que mundo só existe enquanto há presença, enquanto há um ente que, em compreendendo ser, é capaz de projetar mundo e deixar que os entes sejam aquilo que eles são. Notoriamente, esta concepção parece estar enquadrada na dicotomia entre sujeito e objeto que marca a modernidade, posto que não há nada mais tipicamente moderno que a atribuição de papel de formador de mundo a um ente com estruturas subjetivas. Diante disto, devemos lembrar que Heidegger não faz uma filosofia do ser humano ou do homem, não podemos esquecer que a identificação de presença com homem é um equívoco pois não é arbitrariamente que o filosofo decide fazer uso da primeira palavra. Como vimos, a presença possui uma essência extática, e nesse sentido mal podemos continuar a usar o termo "essência", trata-se de um ente singular que apenas é ao existir, diferentemente das 
compreensões antropológicas que tomam o homem como algo por si mesmo evidente. Devemos ainda lembrar que o mencionado privilégio atribuído à presença em Ser $e$ Tempo - privilégio de ser um ente que, ao mesmo tempo em que se encontra entre os demais entes, compreende o ser dos entes - não configura um caso de antropocentrismo, pois, uma vez mais, só poderíamos permitir tal interpretação caso a presença fosse um tipo de homem.

Por outro lado, quando nos atentamos para aquela crítica, compartilhada por Husserl - qual seja, a mencionada antropologia encontrada na analítica da existência - podemos construir uma reflexão em outro sentido. Embora Heidegger afirme em diversas ocasiões que a sua obra possui uma unidade, a distinção entre duas fases prevalece como um método de estudo ou como critério de distinção de conteúdo. A classificação entre Heidegger I e Heidegger II toma como pressuposto uma mudança de ponto de vista na obra do filósofo a partir dos anos 30. Na primeira fase, teríamos Ser e tempo e sua proposta de pensar o sentido de ser a partir de ente presença, já nas décadas posteriores, após a "virada" para o Heidegger II, encontraríamos uma investigação que busca o estudo do ser por ele mesmo, isto é, sem vínculos com o homem ou com qualquer outro ente.

Pensando além da autointerpretação proposta pelo próprio filósofo e das críticas apontadas acima, poderíamos pensar que o abandono e inacabamento de Ser e Tempo podem ter sido motivados por um entendimento de que uma filosofia que fala nos caracteres ontológicos do homem, a partir dos quais os entes vem à tona, ainda seria uma filosofia do sujeito. Sendo assim, "a hermenêutica do Dasein (efetivada pela analítica existencial) ainda persistia no âmbito teórico da metafísica ocidental, posto que a descoberta e a revelação do sentido do ser estavam centradas no Dasein." (FERREIRA, 2007, p. 114).

Nesse sentido, ambos autores teriam apresentado uma filosofia fenomenológica como resposta ao avanço inadequado da ciência no campo da filosofia, porém, os dois filósofos, em suas fases iniciais, em algum sentido, não foram capazes de superar o psicologismo, isto é, não foram capazes de realizar de fato aquilo que propuseram. Portanto, à luz das acusações que dirigiram um ao outro, podemos dizer que, Husserl e Heidegger, em certa medida, repetiram aquilo que as suas acusações continham: o primeiro, permanecendo na esfera da subjetividade, e o segundo, desenvolvendo uma filosofia baseada em caracteres humanos. 


\section{Referências Bibliográficas}

DASTUR, Françoise. Husserl: des mathématique a l'histoire. Paris: Presses Universitaires de France, 1995.

DASTUR, Françoise. Critique of anthropologism in Heidegger's thought. In: FAULCONER, James; WRATHALL, Mark. Appropriating Heidegger. Cambridge: Cambridge University Press, 2000.

FERREIRA, Acylene Maria Cabral. Heidegger e o projeto de superação da subjetividade. Princípios: Revista de Filosofia, Natal, v. 24, n.43, jan.-abr. 2017.

HEIDEGGER, Martin. Ser e tempo. 4. ed. Petrópolis: Vozes, 2009.

HEIDEGGER, Martin. Prolegómenos para uma historia del concepto de tiempo. Madrid: Alianza Editorial, 2007.

HEIDEGGER, Martin. Introducción a la investigación fenomenológica. 2. ed. Madrid: Editorial Sintesis, 2006.

HUSSERL, Edmund. Investigações Lógicas. Segundo Volume, parte I. Investigações para a Fenomenologia e a Teoria do Conhecimento. Lisboa: Centro de Filosofia da Universidade de Lisboa, 2007a.

HUSSERL, Edmund. Investigações Lógicas. Segundo Volume, parte II. Investigações para a fenomenologia e a Teoria do Conhecimento. Lisboa: Centro de Filosofia da Universidade de Lisboa, 2007b.

HUSSERL, Edmund. A filosofia como ciência de rigor. 2. ed. Coimbra: Biblioteca Filosófica, 1965.

PAISANA, João. Fenomenologia e Hermenêutica: a relação entre as filosofias de Husserl e Heidegger. Lisboa: Editorial Presença, 1992.

Autor(a) para correspondência: Ísis Nery do Carmo, Universidade Federal da Bahia, Faculdade de Filosofia e Ciências Humanas, R. Prof. Aristídes Novis, 197, Federação, CEP 40210-909, Salvador BA, Brasil. isisnery@hotmail.com 